\title{
THE NZGEOID09 MODEL OF NEW ZEALAND
}

\author{
S.J. Claessens ${ }^{1}$, C. Hirt ${ }^{1}$, M.J. Amos ${ }^{2}$, W.E. Featherstone ${ }^{1}$, J.F. Kirby ${ }^{1}$ \\ ${ }^{1}$ Western Australian Centre for Geodesy \& The Institute for Geoscience Research, \\ Curtin University of Technology, GPO Box U1987, Perth, WA 6845, Australia \\ ${ }^{2}$ Land Information New Zealand, PO Box 5501, Wellington 6145, New Zealand
}

\section{ABSTRACT}

The NZGeoid09 gravimetric quasigeoid model of New Zealand was computed through FFT-based Stokesian integration with a deterministically modified kernel and an iterative computation approach that accounts for offsets among New Zealand's 13 different local vertical datums (LVDs). NZGeoid09 is an improvement over the previous NZGeoid05 due to use of the EGM2008 and DNSC08GRA models, and due to improvements to the data processing strategy. The integration parameters of degree of kernel modification $L=40$ and cap radius $\psi_{0}=2.5^{\circ}$ were determined empirically through a comparison with 1422 GPS/levelling observations, after the LVD offsets had been removed. The precision of NZGeoid09 was assessed using the same GPS/levelling dataset, yielding an overall standard deviation of $6.2 \mathrm{~cm}$. NZGeoid09 performs better than NZGeoid05 and marginally better than EGM2008, but few data are available in the Southern Alps of New Zealand to give a better evaluation.

KEYWORDS: Quasigeoid determination, New Zealand, GPS heighting, vertical datum unification

\section{INTRODUCTION}

We describe the computation of a new gravimetric quasigeoid model for New Zealand (referred to as NZGeoid09). NZGeoid09 is based on an iterative gravimetric quasigeoid computation approach (Amos and Featherstone 2009) that accounts for offsets among the 13 different local vertical datums (LVDs) used in New Zealand. The computation area spans from $160^{\circ} \mathrm{E}$ to $190^{\circ} \mathrm{E}$ and from $25^{\circ} \mathrm{S}$ to $60^{\circ} \mathrm{S}$. NZGeoid09 has a spatial resolution of $1^{\prime} \mathrm{x} 1^{\prime}$, as opposed to $2^{\prime} \mathrm{x} 2^{\prime}$ for NZGeoid05 (Amos and Featherstone 2009). This better models the short-wavelength portions of New Zealand's gravity field, and reduces interpolation errors for users.

The improvement of NZGeoid09 over NZGeoid05 comes about because of new input data and changes to the computation strategy and software. The input data improvements are the use of the EGM2008 global gravity model (Pavlis et al. 2008) and DNSC08GRA gravity anomalies in marine areas (Andersen et al. 2009). The computational improvements include refined quasigeoid computation software, use of DNSC08GRA to avoid spurious features during the gridding of land gravity data near the coastlines, computation of rigorous area mean values of land gravity anomalies, and computation of precise EGM2008 gravity anomaly area mean values in ellipsoidal approximation.

The entire quasigeoid computation process and its use to determine offsets among the 13 LVDs will be described in this paper. Although termed NZGeoid09, it is actually a gravimetric quasigeoid model. This is deliberate so that lay users do not have to concern themselves with the intricacies of the geoid versus the quasigeoid. As in most other countries, it is widely understood that a geoid is needed to transform GNSS (Global Navigation Satellite System) heights. Land Information New Zealand (LINZ) chose to put 'geoid' in the title because (1) few users know what a quasigeoid is, and (2) it made the name too long. LINZ received no negative feedback on this contradiction, as was the case of NZGeoid05. 


\section{DATA SOURCES}

Land gravity: On land (North Island, South Island, Stewart Island and the Chatham Islands) and in some parts of the littoral zone, a total of 40,737 gravity observations are available at an estimated accuracy level of 0.1-0.5 mGal (Amos 2007) with respect to IGSN71.

Marine gravity: Over marine areas, the altimetry-based DNSC08GRA free-air anomaly grid (Andersen et al. 2009) is available at a spatial resolution of 1'x1'. This model uses retracked multi-mission altimeter data, which can improve the gravity anomalies in the coastal zone (cf. Hwang et al. 2008).

Terrain corrections: For the North and South Islands, there are $621^{\circ} \times 1^{\circ}$ tiles containing gravimetric terrain corrections computed by prism integration (Amos 2007). These are used for the conversion of simple Bouguer anomalies to refined Bouguer anomalies, and as approximations of the Molodensky G1 term in quasigeoid computation (cf. Sideris 1990).

Digital elevation model (DEM): For the North and South Islands, a $56 \mathrm{~m}$ resolution DEM is available. This DEM was used to compute the above terrain corrections, and here to reconstruct terrain-corrected Molodensky free-air anomalies from the gridded refined Bouguer anomalies (cf. Featherstone and Kirby 2000).

Earth gravitational model (EGM): The EGM2008 global geopotential model (Pavlis et al. 2008), to spherical harmonic degree and order 2160 (wavelengths $>\sim 10 \mathrm{~km}$ ), provides the long- and most of the medium-wavelength components of NZGeoid09.

GPS/levelling: Discrete quasigeoid heights determined from spirit-levelled normalorthometric heights (on the different LVDs) and NZGD2000 ellipsoidal heights at 1422 stations on the North and South Islands and Stewart Island/Rakiura (none on the Chatham Islands)). These serve as a 'benchmark' for quasigeoid testing and, importantly, enable iterative quasigeoid computation with LVD unification.

\section{DATA PREPARATIONS}

The approach to quasigeoid computation in New Zealand is different to that used in most other regions, as it has been driven by the 13 offset LVDs. The iterative quasigeoid computation scheme (Amos and Featherstone 2009) applies a correction to the gravity data with LVD offsets computed from the GPS/levelling and quasigeoid from the previous iteration. The computations are performed iteratively until the LVD offset values (the mean of the residuals between GPS/levelling and the gravimetric quasigeoid) no longer change significantly.

Figure 1 summarises the computational scheme used for NZGeoid09, which will be described in more detail in the following paragraphs.

The New Zealand land gravity anomalies have been sorted separately for the 13 different LVDs according to the assumed boundaries among them plotted in Amos and Featherstone (2009). The simple Bouguer anomalies are converted to refined Bouguer anomalies through addition of the gravimetric terrain corrections, interpolated bilinearly to the gravity observation locations from the pre-computed grid of terrain corrections. 


\section{Flowchart NZGeoid09}

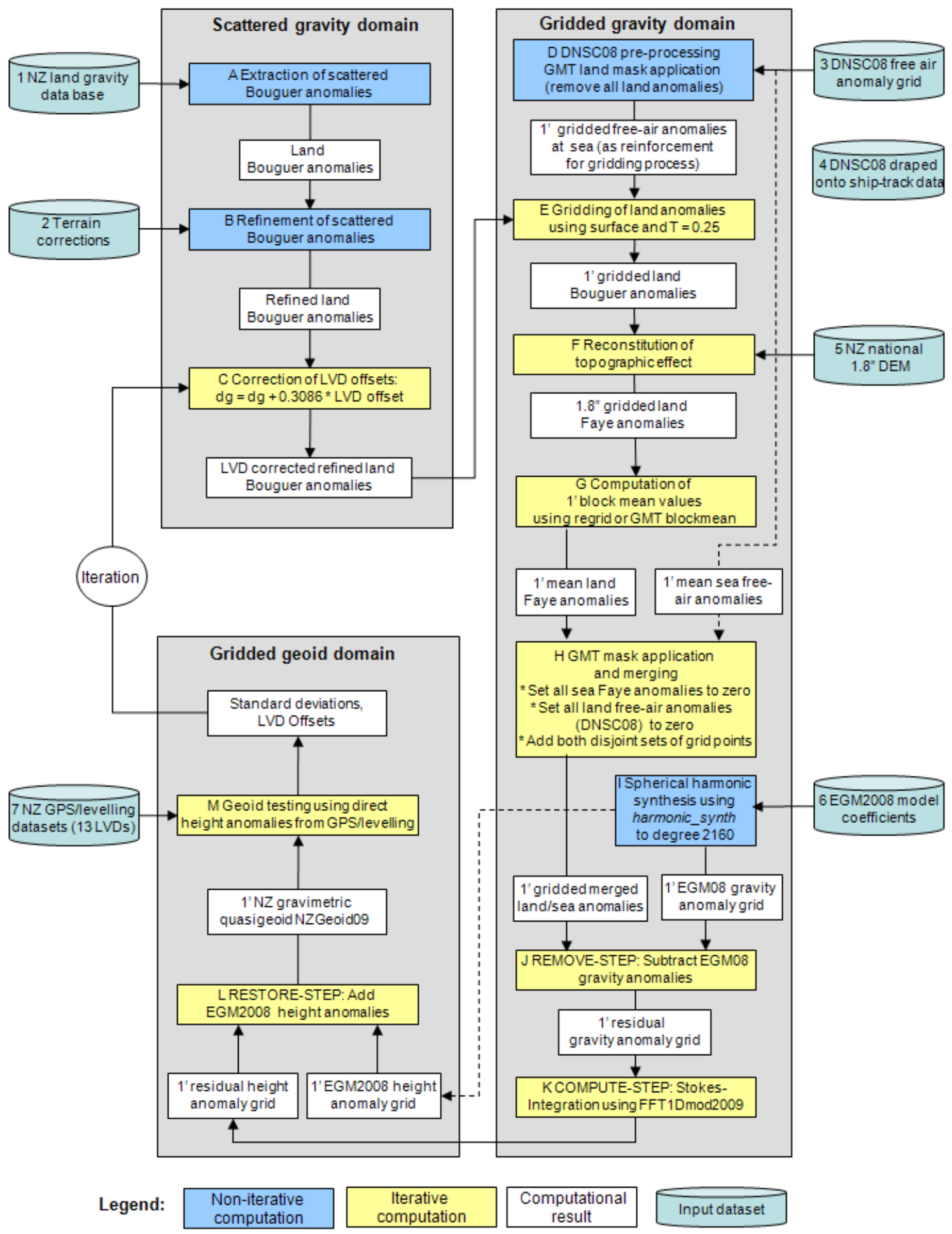

Fig. 1. Flowchart for the computation of NZGeoid09 (from Claessens et al. 2009)

The LVD correction takes into account that heights of the 13 sets of gravity data are with respect to different LVDs and thus do not form a consistent dataset. The impact of the LVD offset on the gravity anomalies is computed using the linear approximation of the free-air gravity correction $(\delta \Delta g=0.3086 \cdot O$, where $o$ is the offset between the quasigeoid and the LVD). For each of the 13 LVDs, individual values for $o$ and thus corrections $\delta \Delta g$ are applied to the gravity anomalies. Comparison of each computed quasigeoid with GPS/levelling stations yields a set of residuals. The mean 
of these residuals was used as a measure of the LVD offset $o$ and are reintroduced in an iterative quasigeoid computation. This is shown schematically in Figure 2, but see Amos and Featherstone (2009) for the theoretical details.

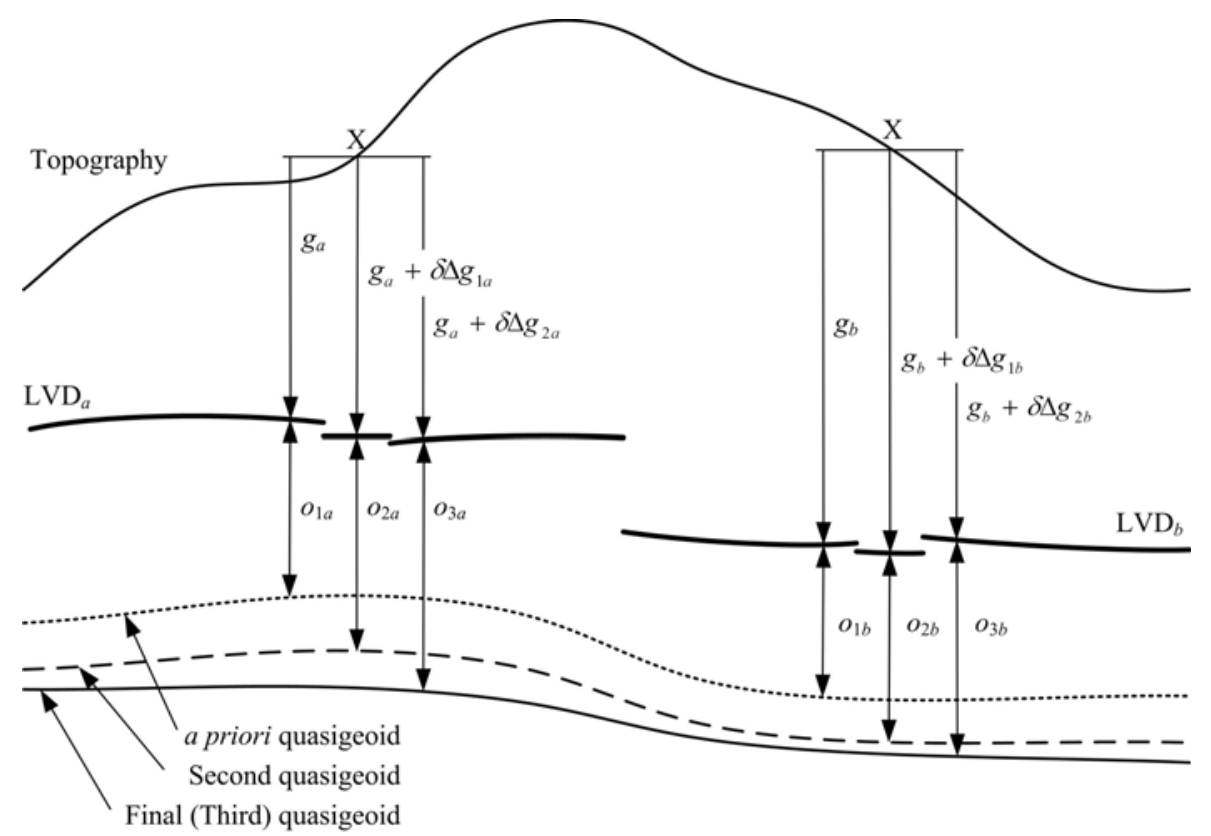

Fig 2. Iterative quasigeoid datum unification scheme (from Amos and Featherstone 2009)

The grid of refined Bouguer anomalies was interpolated from the scattered point observations using the GMT (Generic Mapping Tools; Wessel and Smith 1998) surface function. This algorithm uses continuous curvature splines in tension with a user-defined tension factor. The tension factor of $T=0.25$ recommended for potential fields was used (Smith and Wessel 1990).

Over the littoral zone and beyond, the gridding of the land Bouguer anomalies can be unreliable due to the distribution of the gravity observation stations causing unwanted extrapolation. Therefore, the land Bouguer anomaly dataset was augmented with DNSC08GRA marine gravity anomalies before interpolation. Figure 3 demonstrates how this approach can support the better interpolation of land Bouguer anomalies, as follows. Figures $1 \mathrm{~A}$ and $1 \mathrm{~B}$ show the scattered and interpolated land Bouguer anomalies in the Northwest Nelson region (South Island). [Notice that the New Zealand gravity database contains observations in the littoral zone, as well as some sea bottom observations.] Figures $1 \mathrm{C}$ and $1 \mathrm{D}$, on the other hand, show scattered and interpolated land Bouguer anomalies supplemented with the DNSC08GRA dataset, where the DNSC08GRA data on land (from EGM2008 only) were excluded using the GMT landmask operation along with the full-resolution GMT coastline (Wessel and Smith 1996). Figure 1E shows the differences between the two interpolated grids (Figs. 1B and 1D), demonstrating that extrapolation errors of the order of $10 \mathrm{mGal}$ are avoided, which would have occurred when gridding (extrapolating) the land only data without DNSC08GRA augmentation, especially in areas with few land gravity observations near the coast. However, altimeter-derived gravity anomalies are generally poorer in the coastal zone, even when re-tracked (cf. Andersen et al. 2009, Hwang et al. 2008), so modelling the geoid and quasigeoid near the coastal zone is always problematic (cf. Hipkin 2000).

To reduce spatial aliasing and to generate mean gravity anomalies needed for numerical convolution integration, area mean gravity anomalies were reconstituted from the gridded refined Bouguer gravity anomalies using the reconstruction technique described in Featherstone and Kirby (2000) with the 56 m DEM. The refined Bouguer 
anomalies were interpolated bilinearly to the centre of each DEM cell, and the topography was reconstituted using the reverse planar Bouguer correction for the DEM element height with a constant topographic mass density of $2670 \mathrm{~kg} \mathrm{~m}^{-3}$.

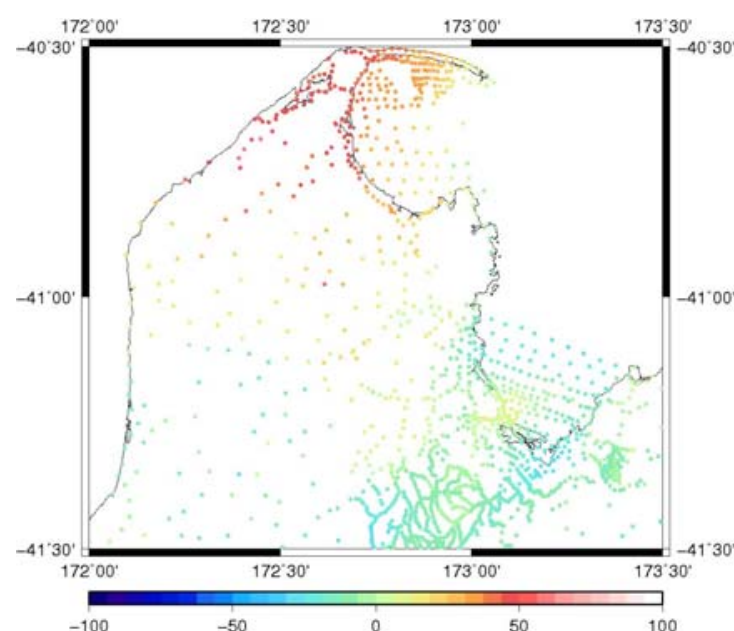

A: Land Bouguer anomalies in the test area

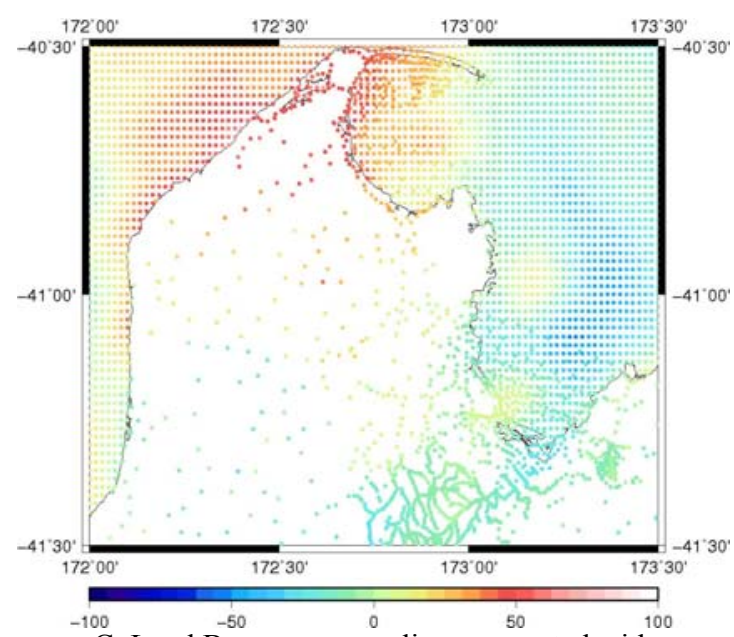

C: Land Bouguer anomalies augmented with DNSC in the test area

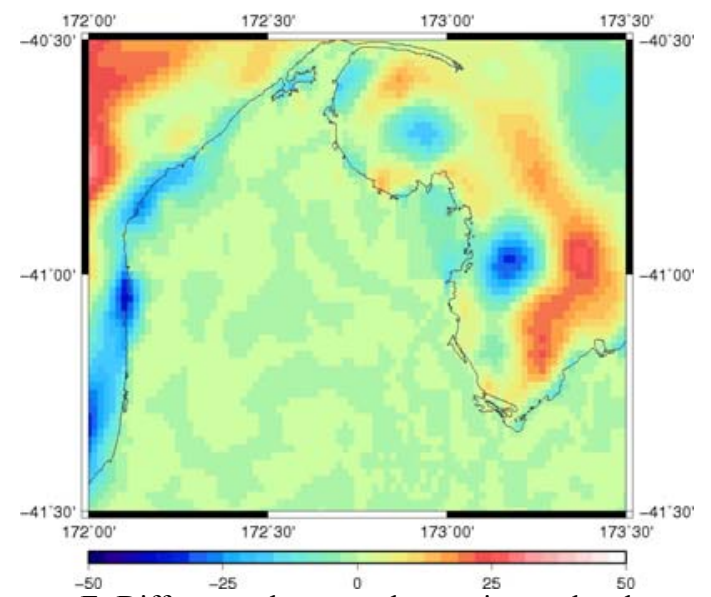

E: Differences between the two interpolated Bouguer anomaly grids

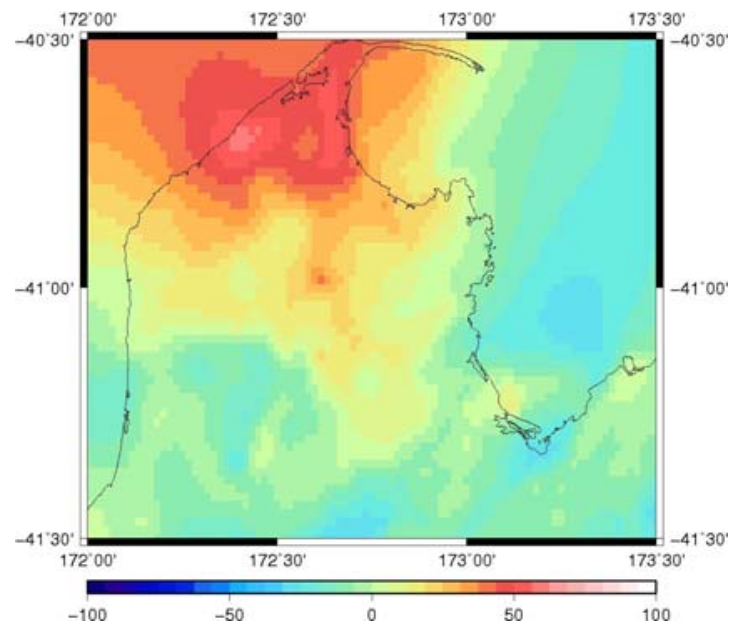

B: Land Bouguer anomalies, from gridding A using surface

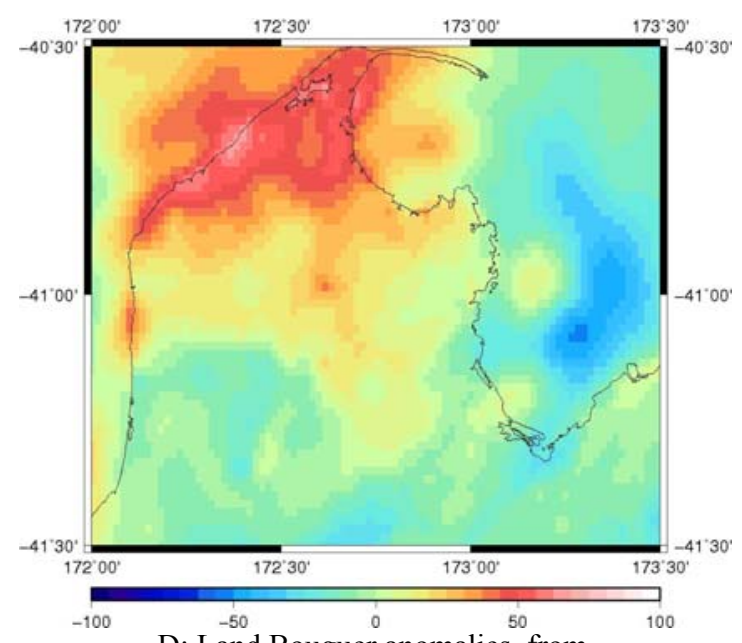

D: Land Bouguer anomalies, from gridding $\mathrm{C}$ using surface

Fig. 3. The effect of not using altimeter data on the interpolation of Bouguer anomalies in a coastal region (Northwest Nelson, South Island) (Mercator projections; units in mGal) 
The $56 \mathrm{~m}$ reconstructed anomaly grid was then generalised to a coarser 1'x1' gridding using in-house regridding software (regrid_sid) that includes proportions of cells along the borders in the computation of the area mean, weighted by the area percentage that is inside the output grid cell. This was selected over the GMT blockmean function, because blockmean does not properly account for input grid cells that are only partly inside the output grid cell. This technique was validated by regridding of area means computed from a series of EGM2008 spherical harmonic coefficients from a 56x56 m resolution to a 1'x1' resolution, followed by a comparison to area means at 1'x1' resolution computed directly from EGM2008. This validation showed that regridding errors using the area-weighted mean are two orders of magnitude smaller than errors using blockmean. In addition, boundary errors resulting from the merger of $621^{\circ} \times 1^{\circ}$ DEM tiles are negligible $(<10 \mu \mathrm{Gal})$.

These reconstructed land anomalies were merged with DNSC08GRA using the GMT grdlandmask function along with the high-resolution GMT coastline (Wessel and Smith 1998). The land mask is applied to the land anomalies so that all data points in marine areas are set to zero and, complementarily, a sea mask is applied to DNSC08GRA to set all land points to zero. The two were added together to produce the final 1'x1' grid of merged land/sea anomalies.

EGM2008 provides the quasigeoid height and gravity anomaly reference fields for NZGeoid09. The spherical harmonic synthesis was performed using the publicdomain harmonic_synth software provided by the EGM2008 development team (http://earth-info.nga.mil/GandG/wgs84/gravitymod/egm2008/index.html). All data synthesised from EGM2008 were computed in the zero-tide system. The spectral range used is degree and order 2 to 2160 , which corresponds to a minimum spatial resolution of $\sim 5 \mathrm{~km}$. Because of the indeterminate zero degree term, the resulting quasigeoid computation is subject to a vertical offset, which will be discussed later in the context of the LVD offsets.

The gravity anomaly grid computed from EGM2008 consists of 1'x1' area means of gravity anomalies in ellipsoidal approximation. A spherical approximation is not sufficient because it can lead to errors in the quasigeoid of several decimetres (Hipkin 2004, Claessens 2006). Ellipsoidal area means cannot be computed rigorously in harmonic_synth, but were computed by adding an ellipsoidal correction to area means of gravity anomalies in spherical approximation. This ellipsoidal correction consists of the difference between point values in the centre of each cell in ellipsoidal and spherical approximation. Comparison to ellipsoidal area means computed from a dense grid of point values in ellipsoidal approximation over a $2^{\circ} \times 2^{\circ}$ test tile on the South Island $\left(167^{\circ} \mathrm{E}-169^{\circ} \mathrm{E}, 46^{\circ} \mathrm{S}-44^{\circ} \mathrm{S}\right)$ showed that the error in the ellipsoidal correction is negligible $(<10 \mu \mathrm{Gal})$.

In order to obtain the residual gravity anomaly field needed for residual quasigeoid computation via FFT-based Stokesian integration, EGM2008 was algebraically subtracted from the merged land/sea anomalies. Figure 4 shows, for a central part of the NZGeoid09 computation area, that subtraction of EGM2008 removes a large part of the gravity field signal (cf. Table 1), especially in marine areas. The larger residual anomalies on the South Island of New Zealand are due to the rugged topography in this part of the world, which the EGM2008 model cannot resolve (because of the omission error). 
Table 1. Descriptive statistics of the NZ land/sea anomalies, EGM2008 gravity anomalies and the residual gravity anomalies (units in $\mathrm{mGal}$ )

\begin{tabular}{lcccc}
\hline grid & min & max & mean & STD \\
\hline Land/sea gravity anomalies & -252.96 & 311.80 & 1.98 & \pm 35.28 \\
EGM2008 gravity anomalies in ellipsoidal approximation & -250.67 & 307.18 & 1.97 & \pm 35.09 \\
Residual gravity anomalies & -186.76 & 143.93 & 0.01 & \pm 4.69 \\
\hline
\end{tabular}

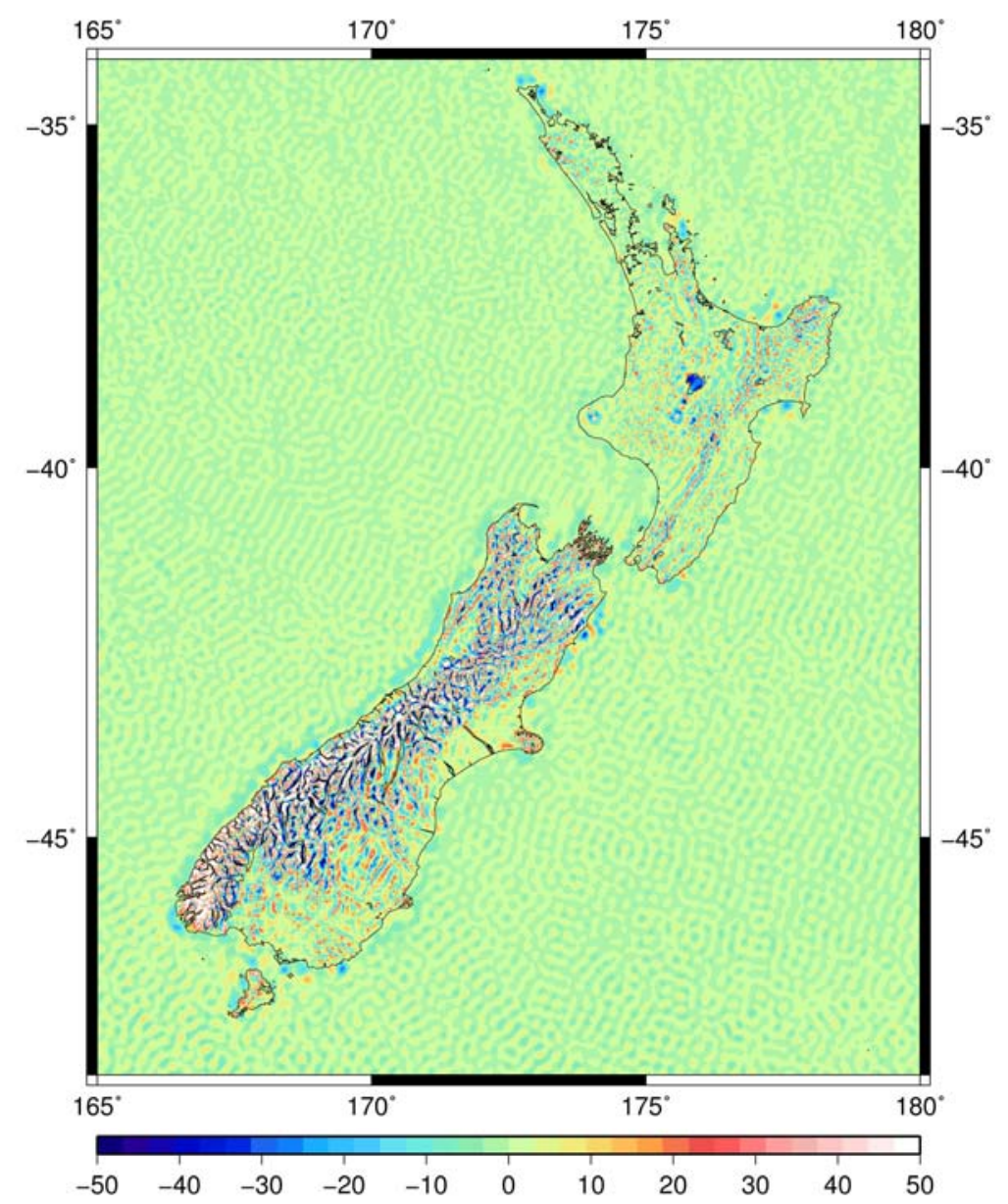

Fig. 4. Grid of residual gravity anomalies in a central part of the NZGeoid09 computation area (Mercator projection, units in $\mathrm{mGal}$ )

\section{QUASIGEOID COMPUTATIONS}

The transformation of mean residual gravity anomalies to a grid of point residual quasigeoid heights is performed using Stokesian integration with a deterministically modified integration kernel (Featherstone et al. 1998), and the 1D fast Fourier transform (FFT) numerical integration technique (Haagmans et al. 1993). Stokesintegrated residual quasigeoid heights with this modified kernel depend on two parameters: $L$ (spherical harmonic degrees removed from the Stokes kernel) and $\psi_{0}$ (integration cap radius).

In summary, the Featherstone et al. (1998) modified kernel combines several existing deterministic modifications into a single scheme. As part of this, the Legendre polynomials up to and including degree $L$ are removed from the spherical Stokes kernel, which improve its long-wavelength filtering of terrestrial gravity data errors (cf. Vanicek and Featherstone 1998), which are better represented by EGM2008. 
However, the choice of this parameter $L$ should not be too large or it causes the modified kernel to oscillate, thus contaminating the numerical integrations, which will be shown later.

The numerical integrations were run on a high-performance supercomputer that is part of the iVEC Western Australian Supercomputer Program (http://www.ivec.org/). We used a 192-CPU SGI Altix 3700 Bx2 computer with 366 GB of RAM. This reduced the computation time to $\sim 6$ hours per parameter combination from $\sim 40$ hours on a $1.6 \mathrm{GHz}$ Sun Ultra 45 workstation with $2 \mathrm{~GB}$ of RAM and $8 \mathrm{~GB}$ of swap. Without the iVEC facility, we would not have been able to run so many combinations of the $L$ and $\psi_{0}$ parameters to search for a locally optimal solution.

Each residual quasigeoid grid from the Stokesian integration was added to the EGM2008 quasigeoid grid to yield a quasigeoid, which was then compared with the 1422 quasigeoid heights from GPS/levelling in an absolute sense (cf. Featherstone 2001). This was done so as to simultaneously optimise the integration parameters and to determine the LVD offsets.

Following Amos and Featherstone (2009), the quasigeoid models are obtained based on iterative computations of the vertical offsets $O$. Introducing $0.00 \mathrm{~m}$ as initial offsets for all 13 LVDs, convergence was again reached after just three iterations. The offsets computed differ considerably from the offsets computed in Amos and Featherstone (2009) (Table 2), especially on the North Island, even though offsets of LVDs on the North Island convergence faster than those on the South Island.

To verify the validity of the computed LVD offsets, they were compared with offsets obtained directly by precise levelling between neighbouring LVDs (Table 3). The LVD offsets computed here agree better with the levelling observations than the offsets determined by Amos and Featherstone (2009) in all but three cases. This reflects the better gravimetric quasigeoid results from using newer data and improved computational techniques.

Table 2. $L V D$ offsets obtained after 3 iterations (based on $L=40, \psi_{0}=2.5^{\circ}$ ), as well as the offsets determined by Amos and Featherstone (2009) (units in m)

\begin{tabular}{lrrr}
\hline LVD & Iteration 3 & A\&F 2009 & difference \\
\hline North Island & & & \\
One Tree Point & -0.063 & -0.242 & 0.179 \\
Auckland & -0.339 & -0.491 & 0.152 \\
Moturiki & -0.241 & -0.314 & 0.073 \\
Gisborne & -0.344 & -0.578 & 0.234 \\
Taranaki & -0.315 & -0.451 & 0.136 \\
Napier & -0.203 & -0.301 & 0.098 \\
Wellington & -0.436 & -0.504 & 0.068 \\
\hline South Island & & & \\
Nelson & -0.294 & -0.258 & -0.036 \\
Lyttelton & -0.466 & -0.349 & -0.117 \\
Dunedin & -0.485 & -0.485 & 0.000 \\
Dunedin-Bluff & -0.381 & -0.256 & -0.125 \\
Bluff & -0.360 & -0.376 & 0.016 \\
\hline Stewart Island & -0.385 & -0.400 & 0.015 \\
\hline
\end{tabular}


Table 3. Comparison of differences between LVD offsets obtained after 3 iterations (based on $L=40, \psi_{0}=2.5^{\circ}$ ) to offsets determined by Amos and Featherstone (2009; Table 2) and observed precise levelling offsets (units in $\mathrm{m}$ )

\begin{tabular}{llrrc}
\hline From & To & Iteration 3 & A\&F 2009 & Levelling \\
\hline Auckland & One Tree Point & -0.276 & -0.249 & -0.206 \\
Auckland & Moturiki & -0.098 & -0.177 & -0.070 \\
Gisborne & Moturiki & -0.103 & -0.264 & -0.075 \\
Gisborne & Napier & -0.141 & -0.277 & -0.166 \\
Moturiki & Napier & -0.038 & -0.013 & -0.099 \\
Taranaki & Napier & -0.112 & -0.150 & -0.046 \\
Taranaki & Wellington & 0.121 & 0.053 & 0.147 \\
Taranaki & Moturiki & -0.074 & -0.137 & -0.162 \\
Napier & Wellington & 0.233 & 0.203 & 0.237 \\
Nelson & Lyttelton & 0.172 & 0.091 & -0.027 \\
Lyttelton & Dunedin & 0.019 & 0.136 & -0.071 \\
Dunedin-Bluff & Dunedin & 0.104 & 0.229 & -0.019 \\
Dunedin-Bluff & Bluff & -0.021 & 0.120 & -0.001 \\
\hline
\end{tabular}

The LVD offset values are highly sensitive to the choice of integration parameters $L$ and $\psi_{0}$. This is seen by comparing the offsets obtained from $L=40, \psi_{0}=2.5^{\circ}$ (Table 2) with those obtained from $L=40, \psi_{0}=2^{\circ}$ and $L=100, \psi_{0}=3^{\circ}$ (Table 4). Table 4 shows that the LVDs located on the mountainous South Island are particularly sensitive. This is because the residual gravity anomalies are larger in this region (Fig. 4), so the Stokesian contribution is correspondingly larger (Fig. 5). Therefore, such optimisation experiments are very useful, especially with free access to a supercomputer facility.

Table 4 also lists the LVD offsets obtained from an experimental quasigeoid solution using a truncated EGM2008 reference field up to degree and order $n_{\max }=360$ only, as well as offsets from EGM2008 to degree and order $n_{\max }=2160$. This experiment was performed to verify that the numerical integrations were correct. The fact that the degree of EGM2008 used has little impact on the offsets indicates that the Stokesian integrator software yields results similar to EGM2008 from degree 361 to 2160 , so is functioning properly, at least in this spectral band.

Table 4. LVD offsets based on different integration parameters and different degrees of EGM2008, and LVD offsets obtained from EGM2008 only (units in m)

\begin{tabular}{lccccc}
\hline Model & \multicolumn{3}{c}{ EGM2008 } \\
\hline Model & $\begin{array}{c}L=40 \\
\psi_{0}=2^{\circ}\end{array}$ & $\begin{array}{c}L=40 \\
\psi_{0}=2.5^{\circ}\end{array}$ & $\begin{array}{c}L=100 \\
\psi_{0}=3^{\circ}\end{array}$ & $\begin{array}{c}L=40 \\
\psi_{0}=2.5^{\circ}\end{array}$ & $n_{\max }=2160$ \\
parameters & $n_{\max }=2160$ & $n_{\max }=2160$ & $n_{\max }=2160$ & $n_{\max }=360$ & \\
\hline One Tree Point & -0.062 & -0.063 & -0.060 & -0.064 & -0.066 \\
Auckland & -0.336 & -0.339 & -0.329 & -0.338 & -0.305 \\
Moturiki & -0.236 & -0.241 & -0.230 & -0.246 & -0.219 \\
Gisborne & -0.341 & -0.344 & -0.337 & -0.354 & -0.312 \\
Taranaki & -0.310 & -0.315 & -0.303 & -0.317 & -0.285 \\
Napier & -0.199 & -0.203 & -0.193 & -0.208 & -0.164 \\
Wellington & -0.428 & -0.436 & -0.414 & -0.440 & -0.372 \\
Nelson & -0.281 & -0.294 & -0.260 & -0.307 & -0.197 \\
Lyttelton & -0.440 & -0.466 & -0.398 & -0.473 & -0.245 \\
Dunedin & -0.452 & -0.485 & -0.419 & -0.494 & -0.334 \\
Dunedin-Bluff & -0.336 & -0.381 & -0.267 & -0.392 & -0.120 \\
Bluff & -0.320 & -0.360 & -0.266 & -0.357 & -0.174 \\
Stewart Island & -0.351 & -0.385 & -0.307 & -0.391 & -0.166 \\
\hline
\end{tabular}


A large number (several dozen) of iterative quasigeoid computations were performed using a range of different integration parameters $L$ and $\psi_{0}$ to find the gravimetric quasigeoid model that shows the smallest RMS difference with respect to the GPS/levelling data. In order to profit from all 1422 GPS-levelling points, a 'composite' RMS was computed after the LVD offsets were removed. That is, the mean of the GPS/levelling/quasigeoid differences for each LVD were removed and the RMS recomputed so that it was not contaminated by these offsets.

First, all possible combinations of parameters $L=40,180,360$ and $\psi_{0}=1^{\circ}, 2^{\circ}, 3^{\circ}$, $4^{\circ}, 5^{\circ}, 6^{\circ}$ were used to compute quasigeoid grids; all used the Featherstone et al. (1998) modified kernel. The 'composite' RMS values of the residuals of the quasigeoid models against the GPS/levelling data are listed in Table 5. This first optimisation step covers a broad range of parameter choices and is aimed at roughly identifying which parameters could yield an optimal solution. Then, in a second optimisation step, more parameter choices in the vicinity of the optimum found in the first step are examined to find locally optimal parameters with a higher accuracy. Using this two-step approach, a large parameter space can be searched more efficiently. However, like most other similar optimisation methods, there is no guarantee that the global minimum is attained.

A kernel modification degree $L=40$ gives stable RMS values of $6.2-6.4 \mathrm{~cm}$, whereas higher modification degrees yield some significantly larger RMS errors (Table 5). This is because the modified kernel oscillates more for higher degrees, so its value at the centre of each cell in the numerical integration is not representative of the whole cell (cf. Featherstone 2003). For the larger cap radii $\psi_{0}$ and $L=40$, the RMS values do not vary much. This indicates that there is not much problem with the propagation of low-frequency terrestrial gravity data errors into the solution (Vaníček and Featherstone 1998), indicating that the Amos and Featherstone (2009) iterative technique has effectively accounted for biases in the gravity anomalies caused by the different LVDs.

Table 5 indicates that the optimal integration parameters are likely to be found in the vicinity of $L=40$ and $\psi_{0}=2^{\circ}$. Therefore, the second more focussed optimisation step used all combinations of parameters $L=20,40,60$ and $\psi_{0}=1.0^{\circ}, 1.5^{\circ}, 2.0^{\circ}, 2.5^{\circ}$, $3.0^{\circ}$.

Table 5. RMS errors computed from differences between the GPS/levelling data and different iterative quasigeoid computations with varying integration parameters $L$ and $\psi_{0}$ (units in $m$ )

\begin{tabular}{|c|c|c|c|}
\hline$\psi_{0} \downarrow$ & 40 & 180 & 360 \\
\hline $\mathbf{1}^{\circ}$ & \pm 0.064 & \pm 0.064 & \pm 0.065 \\
\hline $2^{\circ}$ & $\pm \mathbf{0 . 0 6 2}$ & \pm 0.065 & \pm 0.158 \\
\hline $3^{\circ}$ & \pm 0.062 & \pm 0.066 & \pm 0.092 \\
\hline $4^{\circ}$ & \pm 0.063 & \pm 0.064 & \pm 1.283 \\
\hline $5^{\circ}$ & \pm 0.063 & \pm 0.113 & \pm 0.101 \\
\hline $6^{\circ}$ & \pm 0.063 & \pm 0.121 & \pm 0.069 \\
\hline
\end{tabular}

Table 6 shows the results of this second optimisation step, yielding almost identical RMS values of $\sim 6.2-6.4 \mathrm{~cm}$ (cf. Table 5). Hence, there is only a weak dependency of the RMS of the GPS/levelling/quasigeoid differences on the modification parameters used in this more focussed range. The lowest RMS $(6.16 \mathrm{~cm})$ is found for a cap radius of $\psi_{0}=2.5^{\circ}$ and $L$ between 20 and 60 . Based on these results, NZGeoid09 is based on $L=40$ and $\psi_{0}=2.5^{\circ}$. 
Table 6. RMS errors computed from differences between the GPS/levelling data and different iterative quasigeoid computations with varying integration parameters $L$ and $\psi_{0}$ (units in $m$ )

\begin{tabular}{|c|c|c|c|}
\hline$\psi_{0} \downarrow \quad L$ & 20 & 40 & 60 \\
\hline $1.0^{\circ}$ & \pm 0.0636 & \pm 0.0636 & \pm 0.0636 \\
\hline $1.5^{\circ}$ & \pm 0.0621 & \pm 0.0622 & \pm 0.0622 \\
\hline $2.0^{\circ}$ & \pm 0.0617 & \pm 0.0617 & \pm 0.0617 \\
\hline $2.5^{\circ}$ & \pm 0.0616 & \pm 0.0616 & \pm 0.0616 \\
\hline $3.0^{\circ}$ & \pm 0.0622 & \pm 0.0620 & \pm 0.0618 \\
\hline
\end{tabular}

Figure 5 shows the residual quasigeoid heights for $L=40$ and $\psi_{0}=2.5^{\circ}$; the descriptive statistics are shown in Table 7. In Fig. 5, the larger residual quasigeoid heights manifest in the topographically rugged Southern Alps in the South Island of New Zealand, which correlate well with the larger residual gravity anomalies in Fig. 4. Table 7 shows that the contribution of the residual quasigeoid heights is generally quite small, showing that EGM2008 is very effective at modelling most of the quasigeoid signal in New Zealand, hence the omission error (provided by the Stokesian integration up to the discretisation of $1^{\prime} \mathrm{x} 1^{\prime}$ ) is correspondingly small.

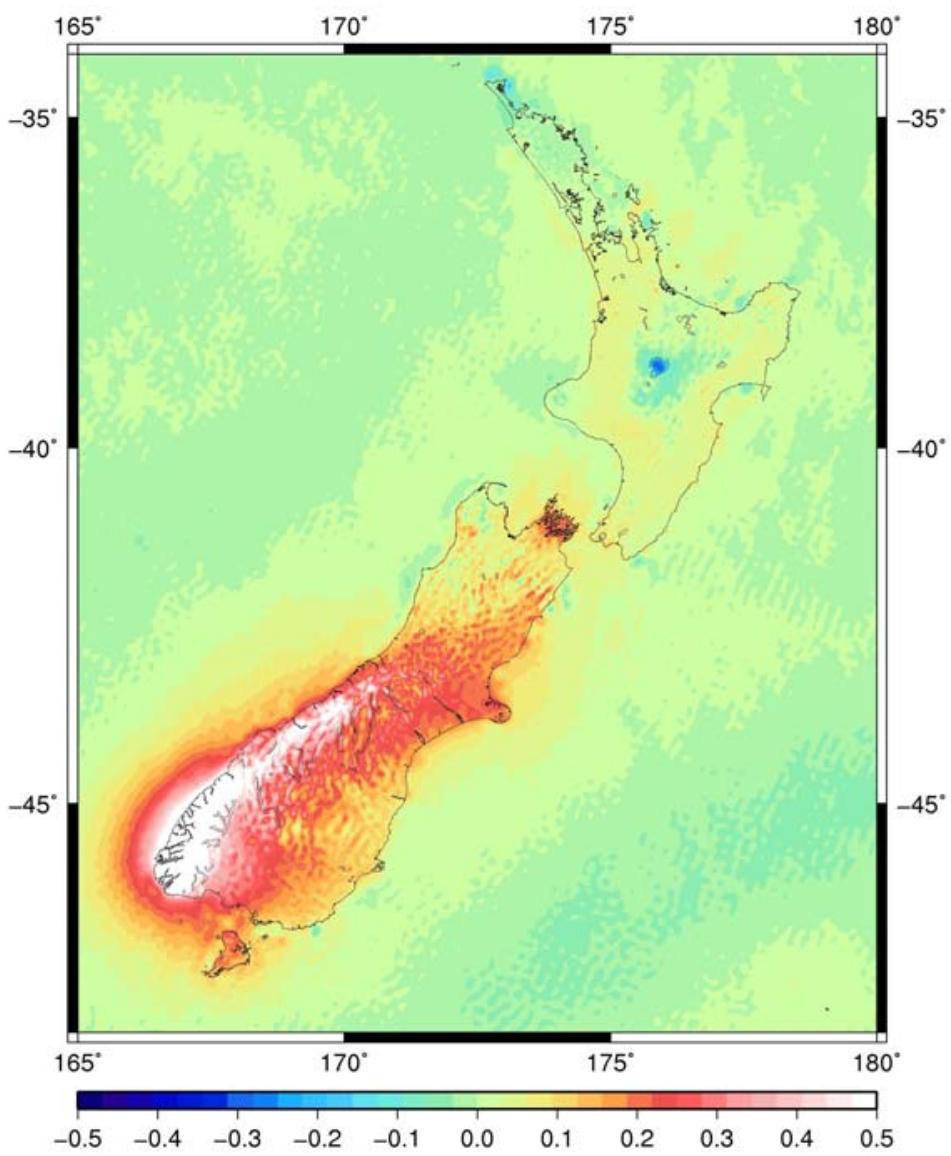

Fig. 5. Residual quasigeoid heights in the central computation area (Mercator projection; units in $\mathrm{m}$ ). 
Table 7. Descriptive statistics of EGM2008 and residual quasigeoid heights (units in $\mathrm{m}$ )

\begin{tabular}{lrrrrr}
\hline grid & min & \multicolumn{1}{c}{ max } & mean & \multicolumn{1}{c}{ STD } & \multicolumn{1}{c}{ RMS } \\
\hline EGM2008 & -46.679 & 54.277 & 5.979 & \pm 28.251 & \pm 28.877 \\
Residual quasigeoid & -1.244 & 1.312 & 0.002 & \pm 0.054 & \pm 0.054 \\
\hline
\end{tabular}

Figure 6 shows NZGeoid09 in the centre of the computation area; the composite descriptive statistics of NZGeoid05 (Amos and Featherstone 2009), NZGeoid09 (here) and EGM2008 only (Pavlis et al. 2008) versus GPS/levelling are in Table 8. From this, NZGeoid09 only gives a marginally lower RMS $(6.2 \mathrm{~cm})$ than EGM2008 (6.4 $\mathrm{cm})$, which is insignificant given the perceived quality of the GPS/levelling data (Amos and Featherstone 2009), showing that EGM2008 is already a good model of the quasigeoid in this region.

This is to be expected because largely the same gravity data have been used in EGM2008 and NZGeoid09, with the main difference that a higher resolution DEM has been used in NZGeoid09, hence the larger residual quasigeoid undulations in the South Island. Also, most of the GPS/levelling points used to generate the statistics in Table 8 are in low-lying regions where the two models are similar (cf. Fig 5). Unfortunately, there is very little coverage of the GPS/levelling observations in the Southern Alps, so it is not so easy to gauge the improvement in regions where the residual quasigeoid contribution is larger. Current work at LINZ is underway to acquire GPS/levelling from hydroelectric power schemes in these regions.

Table 8 also shows the results of two experimental quasigeoid solutions with alternative parameter settings.

- The first (NZG360) is identical to NZGeoid09, except that EGM2008 is used up to degree and order 360 only (instead of 2160). This solution shows only small differences with respect to NZGeoid09, indicating that the Stokesian integration in the spectral range from degree 361 to 2160 gives similar results to spherical harmonic synthesis of EGM2008 coefficients.

- The second (NZG unmodified) is a quasigeoid solution based on Stokesian integration with an unmodified spherical kernel and unlimited cap radius. This is effectively the remove-compute-restore approach that is popular in many other regional quasi/geoid computations. The statistics of this solution show that it does not perform as well as NZGeoid09 and even worse than EGM2008, indicating that the modified kernel is better suited to the integration of residual gravity anomalies than the unmodified kernel (cf. Vanicek and Featherstone 1998), at least in New Zealand.

However, caution must be exercised before generalising this observation because of the error budgets associated with the GPS and levelling data. 


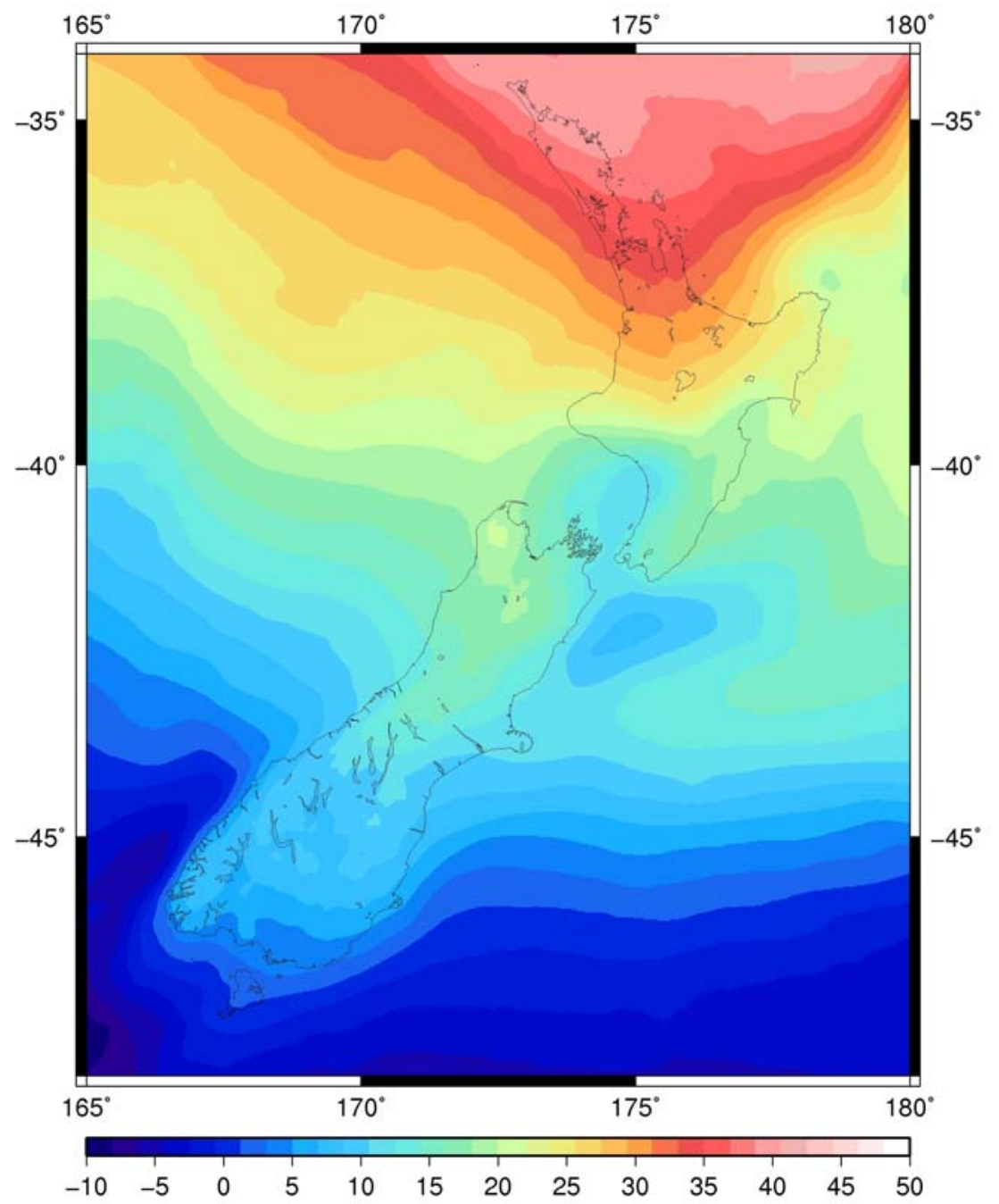

Fig. 6. NZGeoid09 quasigeoid heights in the central computation area (units in $\mathrm{m}$ )

Table 8. Composite descriptive statistics of NZGeoid05, EGM2008 and NZGeoid09, as well as two experimental quasigeoids with alternative parameter choices, versus 1422 GPS-levelling observations (units in m)

\begin{tabular}{lrrrr}
\hline model & min & max & mean & RMS=STD \\
\hline NZGeoid05 & -0.316 & 0.361 & 0.000 & \pm 0.079 \\
EGM2008 & -0.284 & 0.337 & 0.000 & \pm 0.064 \\
NZGeoid09 & -0.378 & 0.280 & 0.000 & \pm 0.062 \\
NZG360 (experimental) & -0.369 & 0.348 & 0.000 & \pm 0.063 \\
NZG_unmodified (experimental) & -0.426 & 0.304 & 0.000 & \pm 0.066 \\
\hline
\end{tabular}

\section{SUMMARY}

NZGeoid09 is a 1'x1' gravimetric quasigeoid model for New Zealand computed using the iterative strategy of Amos and Featherstone (2009) that accounts for the 13 offset LVDs. EGM2008 is used up to degree and order 2160 as a reference model. Terraincorrected land gravity anomalies and marine gravity anomalies from DNSC08 were used in a Stokesian integration with the deterministically modified kernel of Featherstone et al. (1998). 
Several improvements were made to the processing strategy used for NZGeoid05. Most notably, the interpolation of land gravity anomalies in coastal areas is augmented through use of DNSC08 marine gravity anomalies, area means of reconstituted Faye anomalies are computed using a sophisticated regridding technique, and area means of gravity anomalies from EGM2008 are computed ellipsoidally. Other refinements to the computation software were also used.

The optimal Stokesian integration parameters of degree of modification $L=40$ and cap radius of $\psi_{0}=2.5^{\circ}$ were determined empirically through a comparison with 1422 GPS/levelling observations across New Zealand. The overall precision of NZGeoid09 was assessed using the same GPS/levelling dataset, yielding an RMS of $6.2 \mathrm{~cm}$ after removal of the LVD offsets. NZGeoid09 performs marginally better than EGM2008, but few data are available in the Southern Alps to give a better evaluation.

\section{ACKNOWLEDGEMENTS}

WEF, SJC and CH would like to acknowledge Australian Research Council grant DP0663020 and research-contract funding from LINZ. This is TIGeR publication number $\mathbf{x x x}$.

\section{References}

1. Amos, M. J., 2007. Quasigeoid Modelling in New Zealand to Unify Multiple Local Vertical Datums. PhD thesis, Curtin University of Technology, Perth, Australia.

2. Amos, M. J. and Featherstone, W. E., 2009. Unification of New Zealand's local vertical datums: iterative gravimetric quasigeoid computations. Journal of Geodesy 83 (1): 57-68, doi: 10.1007/s00190-008-0232-y.

3. Andersen, O. B., Knudsen, P. and Berry, P. A. M. (2009) The DNSC08GRA global marine gravity field from double retracked satellite altimetry, Journal of Geodesy (online first), DOI: 10.1007/s00190-009-0355-9

4. Claessens, S. J., 2006. Solutions to the ellipsoidal boundary value problems for gravity field modelling. PhD thesis, Curtin University of Technology, Perth, Australia.

5. Claessens, S. J., Hirt, C., Featherstone, W. E. and Kirby, J. F., 2009. Computation of a new gravimetric quasigeoid model. Technical report, Western Australian Centre for Geodesy, Curtin University of Technology, Perth, Australia (http://www.linz.govt.nz/ docs/surveysystem/geodetic/new-gravimetric-quasigeoid-model-for-nz-2009.pdf)

6. Featherstone, W. E., 2001. Absolute and relative testing of gravimetric geoid models using Global Positioning System and orthometric height data. Computers and Geosciences, 27 (7): 807-814, doi: 10.1016/S0098-3004(00)00169-2.

7. Featherstone, W. E., 2003. Software for computing five existing types of deterministically modified integration kernel for gravimetric geoid determination. Computers \& Geosciences, 29 (2): 183-193, doi: 10.1016/S0098-3004(02)00074-2.

8. Featherstone, W. E. and Kirby, J. F., 2000. The reduction of aliasing in gravity anomalies and geoid heights using digital terrain data. Geophysical Journal International, 141 (1): 204-212, doi:10.1046/j.1365-246X.2000.00082.x.

9. Featherstone, W. E., Evans, J. D. and Olliver, J. G., 1998. A Meissl-modified Vaníček and Kleusberg kernel to reduce the truncation error in gravimetric geoid computations. Journal of Geodesy, 72 (3): 154-160, doi: 10.1007/s001900050157.

10. Haagmans, R., de Min, E. and van Gelderen, M., 1993. Fast evaluation of convolution integrals on the sphere using 1D FFT, and a comparison with existing methods for Stokes' integral. Manuscripta Geodaetica, 18: 227-241.

11. Hipkin, R. G., 2000. Modelling the geoid and sea-surface topography in coastal areas, Physics and Chemistry of the Earth 25 (1): 9-16.

12. Hipkin, R. G., 2004. Ellipsoidal geoid computation, Journal of Geodesy, 78 (3): 167179, doi: 10.1007/s00190-004-0389-y. 
13. Hwang, C., Guo, J., Deng, X., Hsu, H. Y. and Liu, Y., 2006. Coastal gravity anomaly from retracked Geosat/GM altimetry: improvement, limitation and the role of airborne gravity data. Journal of Geodesy, 80 (4): 204-216, doi: 10.1007/s00190-006-0052-x.

14. Pavlis, N. K., Holmes, S. A., Kenyon, S. C. and Factor, J. K., 2008. An Earth Gravitational Model to degree 2160: EGM2008. Paper presented at the 2008 General Assembly of the European Geosciences Union, Vienna, Austria, April 13-18, 2008.

15. Sideris, M. G., 1990. Rigorous gravimetric terrain modeling using Molodensky's operator. Manuscripta Geodaetica 15: 97-106.

16. Smith, W. H. F. and Wessel, P., 1990. Gridding with continuous curvature splines in tension. Geophysics, 55 (3): 293-305.

17. Vaníček, P. and Featherstone, W. E., 1998. Performance of three types of Stokes's kernel in the combined solution for the geoid. Journal of Geodesy, 72 (12): 684-697, doi: $10.1007 / \mathrm{s} 001900050209$.

18. Wessel, P. and Smith, W. H. F., 1996. A global self-consistent, hierarchical, and highresolution shoreline database. Journal of Geophysical Research 101 (B4), 8741-8743.

19. Wessel, P. and Smith, W. H. F., 1998. New, Improved Version of Generic Mapping Tools Released. EOS Transactions, American Geophysical Union, 79 (47): 579. 